\title{
Spinal anaesthesia for laparoscopic cholecystectomy: A comparison with general anaesthesia regarding haemodynamic and respiratory stability
}

\author{
Swathi $S^{1}$, Nagaraj A. $\mathbf{2}^{2 *}$, Nataraj M S \\ ${ }^{1}$ Senior Resident, ${ }^{\mathbf{A}}$ Assistant Professor, ${ }^{3}$ Professor, Dept. of Anaesthesia, ${ }^{1}$ Indira Gandhi Institute of Child Health, Bangalore, Karnataka, \\ ${ }^{2,3}$ ESIC Medical College, Bangalore, Karnataka, India \\ *Corresponding Author: Nagaraj A. V \\ Email: drnagaraj1122@yahoo.co.in
}

\begin{abstract}
General anaesthesia has been technique of choice for laparoscopic surgeries. Given the advantages of spinal anaesthesia, we conducted a study to see feasibility of spinal anaesthesia in laparoscopic cholecystectomy in respect to cardiovascular and respiratory stability and post operative outcome. After obtaining institutional ethical committee approval, sixty consenting patients for laparoscopic cholecystectomy were randomized into two groups to receive spinal or general anaesthesia. Spinal anaesthesia was given with $0.5 \%$ bupivacaine heavy and $1 \mu \mathrm{g} / \mathrm{kg}$ clonidine. General anaesthesia group received standard general anaesthesia with endotracheal intubation and positive pressure ventilation. Intraoperative haemodynamics, end tidal and arterial $\mathrm{CO} 2$, postoperative analgesia, satisfaction scores and complications were compared. As per Student t test and Chi square tests demographic, surgical duration, haemodynamic parameters were comparable. Perioperative PaCO2 was stable and comparable. $24 \mathrm{hr}$ visual analog pain scores, tramadol consumption were significantly less in spinal group. Incidence of postoperative nausea and shoulder tip pain was less than $6 \%$ in spinal group. Both groups had good patient and surgeon acceptance.
\end{abstract}

Conclusion: Laparoscopic cholecystectomy can be safely performed under spinal anesthesia and provides good hemodynamic and respiratory stability, requires less postoperative analgesia and better patient and surgeon satisfaction.

Keywords: Clonidine, General anaesthesia Laparoscopic cholecystectomy, Spinal anaesthesia.

\section{Introduction}

Laparoscopic cholecystectomy is the gold standard for surgical treatment of symptomatic gallstones due to the minimally invasive nature of the procedure, less postoperative pain, reduced hospital stay and early return of daily activities. ${ }^{1}$ Until recently the choice of anaesthetic technique for laparoscopic cholecystectomy had been limited to general anaesthesia with muscle relaxation, tracheal intubation and positive pressure ventilation. ${ }^{2}$

Spinal anaesthesia is a less invasive and has lower morbidity and mortality rates as compared to general anaesthesia. Under spinal anaesthesia patient is awake, there is no airway instrumentation, less postoperative pain and absence of nausea and vomiting. ${ }^{3}$ Also the cost effectiveness of spinal anaesthesia makes it an attractive choice. The limiting factor for use of spinal anaesthesia in laparoscopic cholecystectomy was the patient discomfort because of respiratory embarrassment associated with pneumoperitoneum and the shoulder tip pain. ${ }^{5}$

Intrathecal clonidine along with bupivacaine in laparoscopic surgery has been shown to abolish shoulder tip pain and provides good sedation and analgesia in the perioperative period without significant changes in the haemodynamics. ${ }^{4}$ Spinal anaesthesia is shown to preserve diaphragmatic activity in laparoscopic surgery and gas exchange is maintained within physiologic limits without compromising ventilation. ${ }^{6}$

In this background, we designed a study to compare the spinal anaesthetic technique using clonidine as an adjunctive with conventional general anaesthesia for elective laparoscopic cholecystectomy in healthy adult patients.

\section{Materials and Methods}

Institutional ethical committee approval was obtained prior to the study (No. 532/L/11/12/Ethics/Estt.Vol III).

Written informed consent was taken from all the patients after explaining the procedure. Sixty patients of either gender scheduled for elective laparoscopic cholecystectomy aged 18-50 years of either gender with American Society of Anaesthesiologists (ASA) physical status I or II, BMI $<30 \mathrm{~kg} / \mathrm{m}^{2}$, scheduled for elective laparoscopic cholecystectomy were included in the study. Patients with acute cholecystitis/cholangitis/ pancreatitis, known contradiction for pneumoperitoneum, spinal anaesthesia, and previous upper abdominal surgery were excluded from the study.

A thorough preoperative evaluation was done for all the patients on the previous day of surgery and were explained about the procedure. Patients posted under spinal anaesthesia were explained that any pain, discomfort or anxiety will be managed with appropriate medication or converted to general anaesthesia if required. Similarly surgeons were informed to ask for general anaesthesia if there was any technical difficulty during the procedure. All patients were kept nil per oral for $8 \mathrm{hrs}$ for solid foods and 4 hrs for clear fluids and received tab alprazolam $0.5 \mathrm{mg}$ and tab ranitidine $150 \mathrm{mg}$ in the night prior to surgery as premedication.

Patients were randomly allocated into one of the two groups namely spinal anaesthesia (SA) group or general anaesthesia (GA) group by a numbered sealed envelopes. The sealed envelopes were placed in the operating room and opened on patient's arrival. On the day of surgery 
intravenous access was obtained with $18 \mathrm{G}$ IV cannula on the left hand and $500 \mathrm{ml}$ of Ringer's lactate was infused over $15 \mathrm{~min}$. Monitoring included electrocardiogram, noninvasive blood pressure, pulse oximetry, heart rate and endtidal carbon dioxide. 14Fr nasogastric tube was inserted and urinary bladder was catheterized in all the patients.

Patients in spinal anaesthesia group were positioned in right lateral position. Spinal anaesthesia was given with $25 \mathrm{G}$ Quincke spinal needle at $\mathrm{L}_{2}-\mathrm{L}_{3}$ intervertebral space. After confirming free and clear flow of CSF, $3 \mathrm{ml}$ of $0.5 \%$ bupivacaine heavy with $1 \mu \mathrm{g} / \mathrm{kg}$ clonidine was injected intrathecally. Patients were positioned to supine position and table was tilted to 20 degree Trendelenberg position till the sensory block reached T4 dermatome. Pin prick test was performed to evaluate the sensory block level. Once the block level reached T4 dermatome level, the table position was normalized and the surgeons were allowed to proceed with the surgery. If mean blood pressure decreased to less than $60 \mathrm{mmHg}$, ephedrine $6 \mathrm{mg}$ bolus was administered and if heart rate decreased to less than 50 beats per minute atropine $0.6 \mathrm{mg}$ was administered. Patients who experienced intraoperative discomfort like right shoulder pain were initially reassured, when persisted, midazolam $1 \mathrm{mg}$ bolus doses were given intravenously. When the pain still persisted, surgeons were asked to spray the right dome of diaphragm with $10 \mathrm{ml}$ of $2 \%$ lignocaine. In spite of above measures if patient had discomfort and/or if surgeons were not comfortable, it was converted to general anaesthesia.

Patients in general anaesthesia group were induced with injection propofol $2 \mathrm{mg} / \mathrm{kg}$, paralysed with injection vecuronium $0.1 \mathrm{mg} / \mathrm{kg}$ and injection fentanyl $2 \mu \mathrm{g} / \mathrm{kg}$, paracetamol $1 \mathrm{~g}$ intravenously were used for analgesia. After tracheal intubation and confirmation, anaesthesia was maintained with oxygen:nitrous-oxide (40:60) and sevoflurane $1-2 \%$ with positive pressure ventilation using closed circuit. Minute ventilation was adjusted to maintain end tidal $\mathrm{CO}_{2}$ between 35 to $40 \mathrm{mmHg}$. At the end of surgery patients were reversed with neostigmine $0.05 \mathrm{mg} / \mathrm{kg}$ and glycopyrrolate $0.01 \mathrm{mg} / \mathrm{kg}$ and trachea was extubated when patients were awake and comfortable. Blood pressure, oxygen saturation, heart rate, respiratory rate were recorded every 5 minutes. Arterial partial pressure of carbon dioxide was determined in all patients before induction of anaesthesia, half an hour after pneumoperitoneum and in postoperative period.
Intraoperative cardiovascular and respiratory stability and post operative analgesic requirements were considered primary outcome and patient and surgeon satisfaction scores were considered secondary outcome. Uniform technique of laparoscopic cholecystectomy was used with a standard four trocar technique. Carbon dioxide pneumoperitoneum was established by the surgeon to a maximum pressure of $14 \mathrm{mmHg}$ and the surgery was proceeded. Any complication/side effects were noted and treated. Postoperatively pain was managed by intravenous injection tramadol $50 \mathrm{mg}$ as and when required and paracetamol $1 \mathrm{~g}$ intravenous infusion 8th hourly. Other postoperative events related to surgery or anaesthesia such as discomfort, nausea, vomiting, shoulder pain were recorded. The ease and comfort of surgery was asked to be graded by surgeons on a scale of good, average and poor. ${ }^{3}$ At the time of discharge patients were questioned about their degree of satisfaction with the anaesthesia technique on a scale of good, average and unsatisfied (Table 4 included in results).

Data was tabulated in Microsoft Excel and analysed using Minitab version 17. Continuous variables are presented as mean $\pm \mathrm{SD}$, for parametric data and median and $\mathrm{IQR}$, if the data was skewed. Student t test was applied for calculation of statistical significance whenever the data was normally distributed. Mann Whitney U test was applied whenever data was skewed. Categorical variables are expressed as frequencies and percentages. Nominal categorical data between the groups are compared using Chi-square test or Fisher's exact test as appropriate. $\mathrm{p}$ value $<0.05$ is taken to indicate a statistically significant difference.

\section{Results}

All the patients completed the study without any major complications or requiring change of anaesthetic or surgical technique. Student $t$ test has been used for calculation of statistical significance whenever the data followed normative distribution. Mann Whitney test has been applied whenever data followed non-normative distribution. Categorical variables were expressed as frequencies and percentages. Nominal categorical data between the groups were compared using Chi-square test or Fisher's exact test as appropriate. $\mathrm{p}$ value $<0.05$ was taken to indicate a statistically significant difference. The demographic data (Table 1) was comparable between two groups with respect to age, gender, ASA physical status and body mass index.

Table 1: Demographic characteristics

\begin{tabular}{|l|c|c|c|}
\hline \multicolumn{1}{|c|}{ Characteristics } & Group GA $(\mathbf{n}=\mathbf{3 0})$ & Group SA $(\mathbf{n}=\mathbf{3 0})$ & p value \\
\hline Age $($ mean \pm SD) & $38.7 \pm 9.425$ & $37.9 \pm 9.166$ & $0.74 *$ \\
\hline Male & 10 & 10 & \\
Female & 19 & 20 & $0.787^{* *}$ \\
\hline Body Mass Index (mean \pm SD) & $23.67 \pm 3.09$ & $25 \pm 2.71$ & $0.082 *$ \\
\hline ASA Physical Status & 22 & 24 & \\
I & 8 & 6 & $0.542^{* *}$ \\
II & $75 \mathrm{~min}$ & 87.5 & 0.11 \\
\hline Mean duration of surgery (median) & &
\end{tabular}

*student $\mathrm{t}$ test $* *$ Chi Square test 
The intraoperative haemodynamic parameters like heart rate, mean arterial pressure and respiratory rate remained stable and were comparable between both the groups.

The perioperative $\mathrm{PaCO} 2$ levels were comparable and within acceptable levels between both the groups. (Fig. 1).

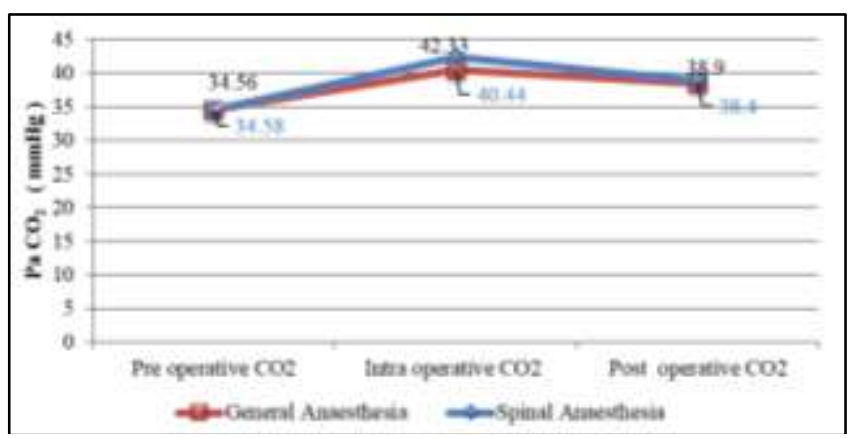

Fig. 1: Trend in the $\mathrm{PaCO}_{2}$ levels between the two groups

The median duration of analgesia (request for first analgesic dose) for the subjects in general anaesthesia and spinal anaesthesia group was 90 and 285 minutes respectively. Patients in spinal anaesthesia group had a significant prolongation of the duration of analgesia. $(\mathrm{p}=0.001)$ (Table 3)

Table 3: Duration of analgesia (time for request of first analgesic dose)

\begin{tabular}{|c|c|c|}
\hline Group & $\begin{array}{c}\text { Duration (minutes) } \\
\text { median }\end{array}$ & p value \\
\hline GA $(\mathrm{n}=30)$ & 90 & 0.001 \\
\hline $\mathrm{SA}(=30)$ & 285 & \\
\hline
\end{tabular}

The Visual Analogue pain score remained below 2 for patients in spinal anesthesia group for $24 \mathrm{hrs}$ as compared to patients in general anesthesia group who had pain scores between 3 to 5 requiring rescue medications. (Fig. 2)

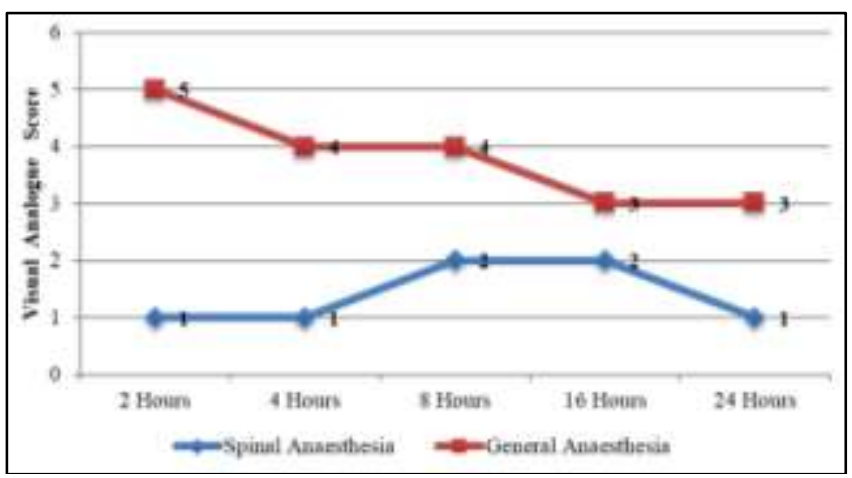

Fig. 2: Visual analogue score among study groups

19 and 11 patients responded as good and averae for spinal anaesthesia as compared to zero and 28 for general anaesthesia. (Table 4).
Table 4: Patient satisfation score

\begin{tabular}{|l|c|c|c|c|}
\hline $\begin{array}{l}\text { Satisfaction } \\
\text { Levels }\end{array}$ & $\begin{array}{c}\text { GA } \\
(\mathbf{n = 3 0})\end{array}$ & $\begin{array}{c}\text { SA } \\
(\mathbf{n = 3 0})\end{array}$ & Total & $\begin{array}{c}\text { P- } \\
\text { Value }\end{array}$ \\
\hline Good & 0 & 19 & 19 & \multirow{2}{*}{0.00} \\
\cline { 1 - 4 } Average & 28 & 11 & 39 & \\
\cline { 1 - 4 } Unsatisfied & 2 & 0 & 2 & \\
\cline { 1 - 4 } Total & 30 & 30 & 60 & \\
\hline
\end{tabular}

\section{Discussion}

We observed patients in spinal anaesthesia group maintained stable haemodynamic and respiratory parameters. Most of the studies have reported the feasibility of performing laparoscopic surgeries under spinal anaesthesia even though concerns like shoulder tip pain, stability of haemodynamic and respiratory parameters exist. ${ }^{6,11,12,7} \mathrm{We}$ used clonidine in a dose of $1 \mu \mathrm{g} / \mathrm{kg}$ as an adjunctive for spinal anaesthesia. Even though we observed a statistically significant decrease in arterial pressure and heart rate in spinal group, out for 30 patients only one required intervention for hypotension and two required treatment for bradycardia. Contrary to the understanding, spinal anaesthesia with clonidine as adjunctive for laparoscopic cholecystectomy provided relatively stable haemodynamics. Ghodki et al documented similar observations in their study on clonidine at $30 \mu \mathrm{g}$ as an adjunctive for spinal anaesthesia in laparoscopic cholecystectomy. ${ }^{7}$

Perioperative respiratory parameters and $\mathrm{PaCO}_{2}$ levels in spinal anaesthesia group were clinically within normal range. In spinal group, even though we did not have control over the respiratory rate, there was no statistically significant difference between the two groups. Patients in spinal group maintained an average rate of 12 to 14 breaths/minute. The end tidal $\mathrm{CO}_{2}$, and $\mathrm{SpO}_{2}$ levels in both the groups were within normal clinical limits.

We monitored arterial partial pressure of $\mathrm{CO}_{2}\left(\mathrm{PaCO}_{2}\right)$ by blood gas analysis to see the effect of either of the anaesthetic techniques on the ability of respiratory system to eliminate $\mathrm{CO}_{2}$. The base-line $\mathrm{PaCO}_{2}$ levels in both groups were similar. Intra-operatively thirty minutes after creating pneumoperitoneum the rise in $\mathrm{PaCO}_{2}$ levels were still within normal limits in both the groups. Intra-operatively, spinal group had a mean $\mathrm{PaCO}_{2}$ level of $42.33 \pm 6.39 \mathrm{mmHg}$. In the postoperative period the mean $\mathrm{PaCO}_{2}$ levels in both the groups were below $40 \mathrm{mmHg}(38 \pm 3.3$ in general anaesthesia group and $38.9 \pm 5.1$ in spinal group). This observation confirms that even though the level of spinal block is at T4 level, patient can still compensate for the increased demand on ventilation by increasing the tidal volume as the rate remained unchanged. Pusapati R N et al observed similar results in their study on gynecologic laparoscopy under SA. ${ }^{6}$

The incidence of shoulder tip pain following SA has been reported to be around $25-48 \%{ }^{8,13}$ Clonidine was tried with bupivacaine as an adjunctive for SA by Ghodki et $\mathrm{al}^{7}$ to abolish the shoulder tip pain. We used a dose of $1 \mu \mathrm{g} / \mathrm{kg}$ clonidine intrathecal for SA group and observed an incidence $6.6 \%$ which is similar to the observations by Ghodki. Two patients in SA group who complained intra- 
operatively about shoulder tip received IV tramadol $50 \mathrm{mg}$, IV midazolam $2 \mathrm{mg}$ and sub-diaphragmatic instillation of 10 $\mathrm{ml}$ of $2 \%$ lignocaine through the port by the surgeon. Twelve patients in GA group had PONV which is about $40 \%$ incidence whereas only one patient in SA group had PONV. The observations were similar to findings in a study conducted by Mehta et al. ${ }^{9}$ Also clonidine used as an adjunctive in SA does not have emetic properties unlike opioids.

The first $24 \mathrm{hr}$ tramadol requirement for analgesia in general anaesthesia group was significantly higher. Patients in the spinal group consistently reported significantly less pain. Tiwari et $\mathrm{al}^{10}$ and Bessa et $\mathrm{al}^{11}$ in similar studies too confirmed that SA results in significantly less post operative pain, compared to that under GA for laparoscopic cholecystectomy. The median tramadol consumption in SA group was also less $(150 \mathrm{mg}$ ) compared to GA group (200 $\mathrm{mg}$ ). The median visual analogue score (VAS) in the SA group ranged between 1-2 score compared to 3-5 score in the GA group over first $24 \mathrm{hr}$ duration (accepatable clinical limit for VAS score is $<3$ ).

The surgeons were satisfied with both the techniques. Patient satisfaction score was also better in SA group due to extended duration of analgesia and less incidence of PONV.

We conclude that laparoscopic cholecystectomy can be safely performed under spinal anaesthesia using bupivacaine and clonidine as an adjuvant. Spinal anaesthesia provides stable intra-operative haemodynamic and respiratory parameters, requires less postoperative analgesics with extended duration of analgesia, with no major complications and has better patient satisfaction.

\section{Conflict of Interest: None.}

\section{References}

1. Lichten JB, Reid JJ, Zahalsky MP, Friedman RL. Laparoscopic cholecystectomy in the new millennium. Surg Endosc 2001; 15:867-72.

2. Imbelloni LE. Spinal anesthesia for Laparoscopic cholecystectomy. Glob J Anesthesiol 2014;1:001-008

3. Yuksek YN, Akat AZ, Gozalan U, Daglar G, Pala Y, Canturk M, Tutuncu T, Kama NA. Laparoscopic cholecystectomy under spinal anesthesia. Am J Surg 2008;195:533-6.

4. Bessa SS, El-Sayes IA, El-Saiedi MK, Abdel-Baki NA, AbdelMaksoud MM. Laparoscopic cholecystectomy under spinal versus general anesthesia:a prospective randomized study. $J$ laparoendosc Adv Surg Tech A 2010;20(6):515-20.

5. Berberoglu M, Dilek ON, Ercan F, Kati I, Ozmen M. The effect of $\mathrm{CO} 2$ insufflation rate on the postlaparoscopic shoulder pain. J Laparoendosc Adv Surg Tech A 1998;8:273-7.

6. Pusapati RN, Sivashanmugam T, Ravishankar M. Respiratory changes during spinal anaesthesia for gynaecological laparoscopic surgery. J Anaesthesiol Clin Pharmacol 2010;26:475-9.

7. Ghodki PS, Sardesai SP, Thombre SK. Evaluation of the effect of intrathecal clonidine to decrease shoulder tip pain in laparoscopy under spinal anaesthesia. Indian J Anaesth 2010;54:231-4.

8. Imbelloni LE, Fornasari M, Fialho JC, Anna RS, Cordeiro JA. General anesthesia versus spinal anesthesia for laparoscopic cholecyctectomy. Rev Bras Anestesiol 2010;60:217-27.
9. Mehta PJ, Chavda HR, Wadhwana AP, Porecha MM Comparative analysis of spinal versus general anesthesia for laparoscopic cholecystectomy: A controlled, prospective, randomized trial. Anesth Essays Res 2010;4:91-5.

10. Tiwari S, Chauhan A, Chaterjee P, Alam MT. Laparoscopic cholecystectomy under spinal anaesthesia: A prospective, randomised study. J Minim Access Surg 2013;9:65-71.

11. Bessa SS, Katri KM, Abdel-Salam, WN, El-Kayal, EA, Tawfik TA. Spinal versus general anesthesia for day case laparoscopic cholecystectomy: A prospective randomised study. $J$ laparoendosc Adv Surg Tech A 2012;22:550-5.

12. Sethi B.S, Samuel M, Sreevastava D. Efficacy of analgesic effect of low dose intrathecal clonidine as adjuvant to bupivacaine. Indian J Anaesth 2007;51:415-9.

13. Turkstani A, Ibraheim O, Khairy G, Alseif A, Khalil N. Spinal versus general anesthesia for laparoscopic cholecystectomy: A cost effectiveness and side effects study. Anesth Pain \& Intensive Care 2009;13:9-14.

How to cite this article: Swathi S, Nagaraj AV, Nataraj MS. Spinal anaesthesia for laparoscopic cholecystectomy: A comparison with general anaesthesia regarding haemodynamic and respiratory stability. Indian $\mathrm{J}$ Clin Anaesth 2019;6(2):254-7. 